\begin{tabular}{|c|c|c|}
\hline 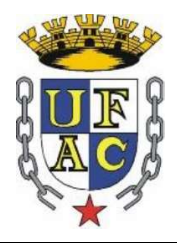 & $\begin{array}{c}\text { UÁQUIRI } \\
\text { Revista do Programa de Pós-Graduação em Geografia } \\
\text { UÁQUIRI - PPGGEO, v. 2, n. 1, p. } 96-111 \text {, ano } 2020 \\
\text { Home page: } \underline{\text { https://periodicos.ufac.br/index.php/Uaquiri }}\end{array}$ & PPG \\
\hline & & $I S S N 2675-4088$ \\
\hline
\end{tabular}

\title{
SOCIEDADE E NATUREZA: A GEODIVERSIDADE E A DINÂMICA DOS CONFLITOS NO PARQUE NACIONAL DA SERRA DO DIVISOR - ACRE - BRASIL
}

\author{
Frank de Oliveira Arcos ${ }^{1 *}$, Alexsande de Oliveira Franco ${ }^{2 *}$ \\ ORCID: https://orcid.org/0000-0002-8801-2940; https://orcid.org/0000-0001-5416-5247
${ }^{1}$ Professor M.sc., Universidade Federal do Acre, Centro de Filosofia e Ciências Humanas, Rio Branco, Acre, doutorando em Geografia - Universidade Estadual de Ponta Grossa. ${ }^{*}$ frankarcos@gmail.com
${ }^{2}$ Professor Dr. Universidade Federal do Acre, Centro de Filosofia e Ciências Humanas, Rio Branco, Acre. * aofrancoufac@hotmail.com

Recebido em: 10/04/2020. Aceito em: 09/05/2020. Publicado em: 22/06/2020 DOI:

\begin{abstract}
RESUMO
A região amazônica passou por diferentes fases de ocupação e transformação da paisagem natural. Essa dinâmica ocorre até os dias de hoje inclusive sobre o patrimônio natural geológico e geomorfológico. Para o domínio amazônico, a Geodiversidade está disposta entre os elementos do meio físico natural, identificado nos arenitos, rochas sieníticas entre sedimentos de origem no Cretáceo. O presente artigo tem o objetivo apresentar a Geodiversidade do Parque Nacional da Serra do Divisor (PNSD) e a dinâmica dos conflitos territoriais internos e do entorno. O PNSD está situado no oeste do Estado do Acre na fronteira com o Peru e cordilheira do Andes, com importante patrimônio natural com relevante potencial Geoturístico dado à paisagem e os elementos resultantes da modelação do relevo esculturado no tempo geológico e na atividade tectônica local, singular do oeste acreano, no bioma Amazônico.
\end{abstract}

Palavras-chave: Serra do Divisor; Geodiversidade; Geoturismo; Conflitos; Parque Nacional.

\section{SOCIETY AND NATURE: THE GEODIVERSITY AND THE DYNAMICS OF CONFLICTS IN THE NATIONAL PARK OF SERRA DO DIVISOR - ACRE - BRAZIL}

\begin{abstract}
The Amazon region has undergone different phases of occupation and transformation of the natural landscape. These dynamics occurs even today on the geological and geomorphological natural heritage. For the Amazonian domain, Geodiversity is disposed among the elements of the natural physical environment, identified in the sandstones, sienitic rocks between sediments of Cretaceous origin. The present article aims to present the Geodiversity of Serra do Divisor National Park (PNSD) and the dynamics of internal territorial conflicts and the environment. The PNSD is located in the western part of the state of Acre on the border with Peru and the Andes, with important natural heritage with relevant geotourism potential given to the landscape and the elements resulting from the modeling of the relief sculpted in the geological time and in the local, unique tectonic activity of the western Acre, in the Amazonian biome.
\end{abstract}

Keywords: Serra do Divisor; Geodiversity; Geotourism; Conflicts; National park 


\section{SOCIEDAD Y NATURALEZA: LA GEODIVERSIDAD Y LA DINAMICA DE LOS CONFLICTOS EN EL PARQUE NACIONAL DE LA SIERRA DEL DIVISOR - ACRE - BRASIL}

\section{RESUMEN}

La región amazónica pasó por diferentes fases de ocupación y transformación del paisaje natural. Esta dinámica ocurre hasta los días de hoy incluso sobre el patrimonio natural geológico y geomorfológico. Para el dominio amazónico la Geodiversidad está dispuesta entre los elementos del medio físico natural, identificado en los arenitos, rocas sieníticas entre sedimentos de origen en el Cretáceo. El presente artículo tiene el objetivo de presentar la Geodiversidad del Parque Nacional de la Sierra del Divisor (PNSD) y la dinámica de los conflictos territoriales internos y del entorno. El PNSD está situado en el oeste del Estado de Acre en la frontera con Perú y cordillera de los Andes, con importante patrimonio natural con relevante potencial Geoturístico dado al paisaje y los elementos resultantes de la modelación del relieve esculturado en el tiempo geológico y en la actividad tectónica local, singular del oeste acreano, en el bioma Amazónico.

Palabras clave: Serra do Divisor; geodiversidad; geoturismo; conflictos; Parque Nacional.

\section{INTRODUÇÃO}

A Geodiversidade no Brasil está diretamente ligada aos aspectos da geoconservação do patrimônio natural geológico e geomorfológico para cada domínio morfoclimático. Para o domínio Amazônico, a Geodiversidade dos elementos naturais observados na geologia e geomorfologia identificadas se particulariza pela ocorrência dentro do Parque Nacional da Serra do Divisor (PNSD) no oeste do Acre, limítrofe ao Peru e cordilheira andina.

Dentro desse contexto, a Geodiversidade se conecta a geoconservação que está ligada à prática do geoturismo com foco na valorização e proteção do patrimônio natural. De acordo com Veiga (2002), a Geodiversidade expressa as particularidades do meio físico natural, abrangendo rochas, relevo, clima, solos, águas subterrâneas e superficiais. Para CPRM (2006), a Geodiversidade é o estudo da natureza abiótica (meio físico), constituída por uma variedade de ambientes, composição, fenômenos e processos geológicos que dão origem às paisagens, rochas, minerais, águas, fósseis, solos, clima e outros depósitos superficiais. Seguindo a mesma direção, Galopim de Carvalho (2007) define a Geodiversidade, sendo o conjunto das rochas, dos minerais e das suas expressões no subsolo e nas paisagens.

No conjunto da Geodiversidade está contido o geoturismo, uma importante ferramenta para o fomento do conhecimento sobre o patrimônio natural elaborado pelos agentes endógenos e exógenos dentro do tempo geológico e geomorfológico, onde, para Moreira (2014), o geoturismo é um novo segmento de turismo em áreas naturais, realizado por pessoas que têm o interesse em conhecer mais os aspectos geológicos e geomorfológicos de um determinado local. 
De acordo com Dowling (2009), o geoturismo consiste em uma prática de turismo sustentável, na apreciação das feições naturais do substrato do planeta Terra, fomentando ao público a compreensão cultural, ambiental e a percepção da necessidade de conservação destas feições.

O PNSD é uma área que apresenta boa potencialidade para empreendimentos geoturísticos, dada a incidência de numerosos atrativos naturais (cânions, cachoeiras, corredeiras, piscinas naturais, cavernas, mirantes etc.), além de terrenos favoráveis à implantação de um geoparque, a despeito de se tratar de uma região virtualmente despovoada (ADAMY, 2015). A descrição do autor citado reforça os elementos da Geodiversidade e de seus aspectos no interior do PNSD onde, os atrativos mencionados apenas podem ser identificados no oeste acreano, demonstrando assim o potencial do geoturismo no Acre.

Nesse contexto, Veras (2014) destaca que ao aplicar a visão geográfica na interpretação das características da paisagem, em seu aspecto geológico e geomorfológico é fundamental para identificar potencialidades para o geoturismo, ofuscado pelo desconhecimento dos gestores e comunidade. Destacado como possibilidades de integração a outros produtos turísticos, em seu uso econômico, científico e pedagógico.

É relevante mencionar que paralelo a essa rica Geodiversidade e potencialidade geoturística na Amazônia inserem-se as comunidades locais, como ribeirinhos, seringueiros, extrativistas, indígenas, além de agricultores e pecuaristas no interior e entorno do Parque Nacional da Serra do Divisor - PNSD.

$\mathrm{Na}$ área do PNSD ocorrem conflitos territoriais entre a gestão do Parque e os respectivos atores sociais locais. Isso ocorre, pois a área é um parque nacional que em seu plano de manejo realizado no final da década de 1998 previa inicialmente a preservação dos recursos naturais e a não ocupação antrópica no interior do parque. No entanto, muito antes da idealização do PNSD como unidade de conservação, em alguns locais se identificou a existência de comunidades, instaladas no interior, às margens dos rios e igarapés, isoladas e muitos dos moradores do parque ainda vivem das pequenas culturas de subsistências: da pesca e do extrativismo, embora incipiente.

Destarte, este trabalho tem como objetivo apresentar a Geodiversidade do Parque Nacional da Serra do Divisor (PNSD) e a dinâmica dos conflitos territoriais. 


\section{MATERIAL E MÉTODOS}

Para o desenvolvimento do presente trabalho foram realizadas algumas etapas: 1) definição da área tendo como objeto de estudo o Parque Nacional da Serra do Divisor (PNSD); 2) Levantamento do material bibliográfico; 3) aquisição e montagem do banco de dados digital cartográfico do PNSD; 4) definição da categoria temática Geodiversidade e Geoturismo no âmbito dos conflitos territoriais; 5) elaboração do presente artigo.

\section{a. Parques Nacionais}

Essa categoria possibilita interação entre visitante e natureza, no entanto, são vedadas modificações no ambiente natural e interferência humana. Há nessas áreas, a possibilidade de atividades diversas desde que monitoradas, segundo a Lei n. 9.985 que criou o Sistema Nacional de Unidades de Conservação (SNUC na década de 2000) que apresentam como objetivo a preservação de ecossistemas naturais de grande relevância ecológica e beleza cênica, possibilitando a realização de pesquisas científicas, atividades de educação, interpretação ambiental, de recreação e de turismo.

O primeiro parque criado no Brasil foi o Parque Nacional de Itatiaia, pelo decreto $\mathrm{n}^{\circ} 1713$ de 14/06/1937, entre os estados do Rio de Janeiro e Minas Gerais. Atualmente, no Brasil encontram-se aproximadamente 72 parques nacionais, distribuídos em todas as regiões e em diferentes biomas. Na Amazônia temos cerca de 20, no estado do Acre encontra-se apenas um parque nacional, o PNSD. Essa Unidade de Conservação possui características peculiares relacionadas à riqueza ambiental de uso indireto baseada na preservação estrita dos recursos naturais.

\section{b. Meio Físico Natural do Oeste Acreano}

O Acre, sem dúvida, se destaca pela presença de localidades fossilíferas disseminadas, a grosso modo, por todo seu território associadas em grande parte à Formação Solimões, mas também a depósitos desde o Cretáceo (como dentes de tubarões encontrados na Serra do Moa) (RANCY, 2000); (RANCY, 2000; CAMPBELL, et al., 2001; SANTOS et al., 1991).

A história geológica da Bacia do Acre envolve primeiramente a deposição de sedimentos na borda de um cráton situado a leste, formando uma bacia marginal, aberta desde o Paleozoico, resultando em sedimentos continentais muito intemperizados, intercalados a sedimentos marinhos (ACRE, 2010). 
No oeste acreano situa-se o "Planalto Residual da Serra do Divisor ocorrendo as Serras do Jaquirana, do Moa, do Juruá-Mirim e do Rio Branco, compreendendo as maiores altitudes da Amazônia Ocidental (entre 270 e 750 m)" (CAVALCANTE, 2006, p.14-15).

Essa área á uma das mais ricas da região amazônica, tanto com relação à biodiversidade, quanto faunística e florística.

\section{c. Comunidades locais}

As comunidades locais na região são diversificadas e numerosas, no local isso não é diferente, encontram-se:

a) Ribeirinhos, as margens dos rios, com atividades relacionadas a pesca e agricultura de subsistência e pequenas criações;

b) Seringueiros e extrativistas, que vivem da coleta no interior da floresta, da caça e da agricultura de subsistência e pequenas criações;

c) Indígenas, no interior da floresta, população abrangente que vivem especialmente da caça e pesca;

d) Agricultores que sobrevivem da agricultura e do excedente da produção que é comercializada nos centros urbanos e, criam pequenos e médios animais.

e) e, Pecuaristas que criam animais de grande porte e possuem extensas áreas de terras. Estes contribuem diretamente com os maiores impactos ambientais e degradação do meio natural, não somente em áreas ambientalmente protegidas.

As comunidades mencionadas possuem particularidades em seus respectivos modos de vida tanto as que se encontram no interior quanto no entorno do PNSD. Ribeirinhos, seringueiros e indígenas possuem maior harmonia com o meio. Por outro lado, o processo de ocupação antrópica vem desde antes da criação do PNSD de certa forma acelerou a dinâmica do uso e ocupação do solo na área. Os pecuaristas são os que desenvolvem atividades mais impactantes no local em função da necessidade de grandes áreas de pastagem. Isso tem trazido conflitos entre os moradores locais e os gestores da área.

Não podemos deixar de destacar a ação de invasores que acessam a área do PNSD via estradas clandestinas, rios e igarapés. Essa ação visa o corte e retirada de madeira de altíssimo 
valor comercial, como o cedro, cerejeira, castanheiras e mogno, deixando marcas pontuais no interior do parque com os registros da devastação, com resultado o desmatamento.

\section{d. Localização do Parque Nacional da Serra do Divisor (PNSD)}

O PNSD localiza-se a oeste no Estado do Acre (Figura 1). Foi criado pelo decreto $\mathrm{n}^{\mathrm{o}}$ 97.839 de 16 de junho de 1989 e encontra-se distante aproximadamente $70 \mathrm{~km}$ do centro urbano mais próximo. "A área do parque abrange terras dos municípios de Cruzeiro do Sul, Mâncio Lima, Rodrigues Alves, Porto Walter e Marechal Thaumaturgo, municípios que fazem parte da microrregião de Cruzeiro do Sul. O PNSD ainda faz fronteira com o Peru em toda sua porção ocidental" (LIRA, 2015 p.143).

O Parque Nacional da Serra do Divisor possui superfície de 843.012,28 hectares. Seu nome originou-se de uma importante característica geomorfológica que existe na área, a região divortium aquarum (divisor de águas) das bacias hidrográficas do Médio Vale do Rio Ucayali, no Peru e do Alto Vale do Rio Juruá, Acre/Brasil (Associação SOS Amazônia et al., 1998).

\section{e. Procedimentos Operacionais}

A área de estudo foi escolhida a partir de critérios que contemplam os elementos que compõem o patrimônio natural existente no Parque Nacional da Serra do Divisor (PNSD) no contexto geológico-geomorfológico e geoturístico no estado do Acre.

O material bibliográfico da literatura nacional, regional e local que contém informações sobre a Geodiversidade e o patrimônio natural do PNSD foi selecionado no RADAMBRASIL, folha SB/SC.18 Javari/Contamana; dados do Zoneamento ecológico-econômico do Acre/ZEE e, boletins da EMBRAPA sobre a evolução da paisagem no Acre. Os dados digitais em formato shapefile sobre a localização e delimitação do PNSD foram obtidos junto ao Instituto Chico Mendes de Conservação da Biodiversidade - ICMBio. Com as imagens do satélite LANDSAT 7 que foram extraídas do site do INPE (Instituto Nacional de Pesquisas Espaciais), órbita/ponto $(5 / 65 ; 5 / 66 ; 5 / 67 ; 6 / 65$ e 6/66) do sensor TM (Thematic Mapper) se produziu um mosaico que contempla o Vale do Juruá e os limites do PNSD.

Utilizamos também alguns dados do ZEE contendo a rede hidrográfica e delimitação política dos municípios inseridos na área do parque. Com base nos dados selecionados, foi possível organizar e elaborar em ambiente SIG e, com o suporte do software de 
geoprocessamento ArcGIS versão 10.3, desenvolvido pela ESRI (Environmental Systems Research Institute) o mapa das características do patrimônio natural geológico, geomorfológico e de uso e ocupação fundiária do PNSD que será apresentado no item resultados e discussões desse artigo.

A categoria temática Geoturismo foi eleita por ter maior relação na expressão do patrimônio natural e da Geodiversidade geológica e geomorfológica de inúmeras áreas no território brasileiro. Para o caso do PNSD no estado do Acre ela se torna importante por ter expressão dentro do contexto turístico regional, uma vez, identificada as características da geologia e geomorfologia do Parque Nacional da Serra do Divisor.

\section{RESULTADOS E DISCUSSÕES}

\section{a. Características da Geodiversidade do PNSD}

No Acre, encontram-se três regiões geologicamente distintas: a área das serras Rio Branco, Juruá-Mirim, Moa e Jaquirana, que constituem, regionalmente, o Complexo Fisiográfico da Serra do Divisor, as quais são formadas principalmente por sedimentos do Cretáceo e pequenas ocorrências do Pré-Cambriano e do Paleozoico; e as áreas com relevo mais suave, distribuídas na maior parte do Estado e representadas por sedimentos das formações Ramon e Solimões, e a terceira - áreas aluviais formadas pelos terraços fluviais e áreas aluvionares (ACRE, 2000).

Na Serra do Divisor, noroeste do Acre, a zonação altitudinal e pedológica é básica para o entendimento das diferentes formações florestais ocorrentes. Na classificação Köppen, é uma área com clima do tipo A (clima tropical chuvoso), dos subtipos Am (monção - com uma estação seca curta, mas com precipitação elevada suficiente para manter as florestas tropicais) e Af (floresta - com altas temperaturas, muita chuva e amplitude térmica dos meses mais quentes e mais frios, menor que $5^{\circ} \mathrm{C}$ ). Esta região constitui uma primeira barreira geográfica para as massas de vapor d'água vindas do leste amazônico, atingindo cerca de 700 metros de altitude no território brasileiro, em condições favoráveis às formações de florestas nebulares (cloud forest). Tais ambientes, conhecidos na região oriental da Cordilheira Andina Amazônica como "bosques de ceja" ou "ceja andina", ocupam uma faixa altitudinal aproximada entre 600 a 2.000 metros, caracterizadas por uma grande variedade de epífitas (destacando a família das Bromeliaceae), líquens, musgos e espécies arbóreas de menor porte e com dossel aberto. 
No Brasil, as evoluções das paisagens em escala espaço-temporal imprimem aos lugares marcas próprias de sua intrínseca Geodiversidade no contexto do geoturismo e, dos elementos característicos da geologia e geomorfologia de cada região, que, nesse caso, enfatizamos o Parque Nacional da Serra do Divisor (PNSD) no Acre, sudoeste da Amazônia brasileira. No estado do Acre, "desenvolve-se um conjunto serrano bastante movimentado por eventos tectônicos, com diferenças de cotas superiores a 600 metros, denominado serra do Divisor. Essa serra contempla numerosos sítios de real interesse para a introdução do ecoturismo" (ADAMY, 2015b, p. 270).

Os elementos característicos da geologia no PNSD têm intrínseca especificidade no contexto evolutivo da paisagem, ocorrendo em sinergia aos processos resultantes da atividade tectônica nos Andes peruanos que, com isso, podem-se identificar na área do parque algumas cachoeiras, grutas e afloramentos rochosos que existem somente nesta parte do Acre. Aliás, é nessa microrregião denominada vale do Juruá que se encontram as maiores altitudes do Estado e, outra microrregião, o vale do Acre, tem altitudes estimadas em 300 metros.

Quanto aos aspectos da geomorfologia da área do PNSD, o relevo bastante movimentado que se apresenta em colinas formando vales onde o controle estrutural orienta os rios e igarapés, que correm sobre rochas metamórficas e sedimentares. Muitos desses rios apresentam coloração escura decorrente do contato e das ações físico-químicas da água na rocha.

A paisagem acreana é fruto de profundas modificações no tempo geológico que estão presentes por todo Acre, em especial, os elementos da Geodiversidade natural no contexto geológico-geomorfológico, onde, destacamos (Figura 1) elaborada com base em Adamy (2015) a Cachoeira do ar-condicionado (A) sobre os arenitos da formação Moa, que entre as demais existentes na área é uma das mais procuradas por visitantes; (B) sobre rochas sieníticas, a cachoeira Formosa no leito do rio Anil; (C) Buraco da Central, furo de uma sondagem realizada pela Petrobrás que alcançou o lençol freático e, a água jorra initerruptamente dentro do Parque Nacional da Serra do Divisor. 
Figura 1: Elementos da Geodiversidade/ PNSD, Acre/Brasil.

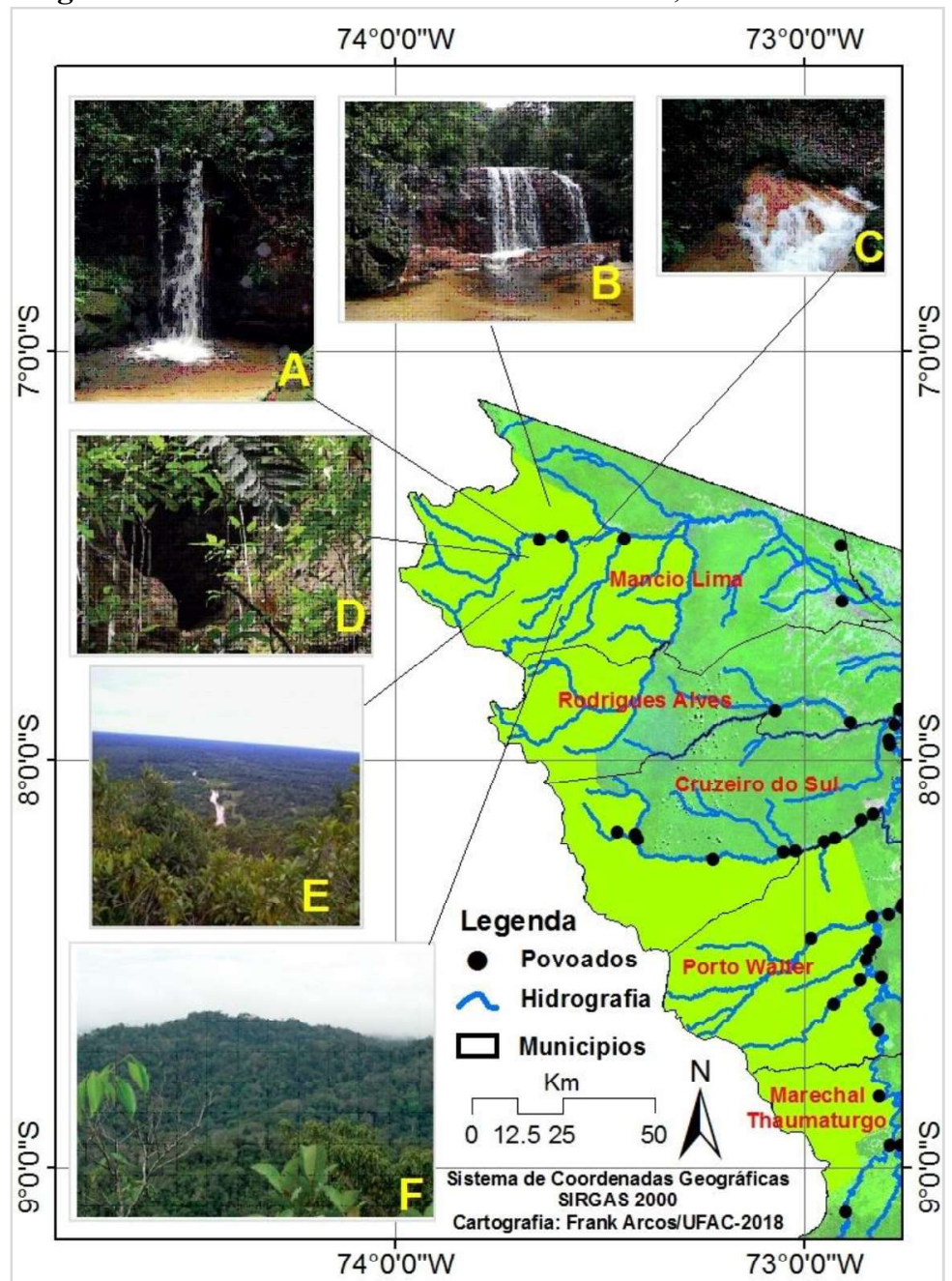

Fonte: ACRE/ZEE (2010); Adamy (2015); Lira (2015). Org. pelos autores (2018).

$\mathrm{Na}$ imagem (D) uma pequena gruta localizada nos arenitos da formação Moa que merece estudos espeleológicos; (E) Vale do rio Moa e sua planície de inundação que na cheias dos rios na Amazônia chega ao interior da floresta; (F) Conjunto de colinas em meio a sedimentos do cretáceo no Parque Nacional da Serra do Divisor (ADAMY, 2015 p. 164-165 e 167) que, representam as características principais e positivas voltadas para a dinamização do geoturismo no PNSD.

O conjunto que engloba o bordo oriental da Serra da Jaquirana denominada localmente de "Pé da Serra", o conhecido Igarapé do Amor e a trilha Anil até a altura da Cachoeira do Pedernal. Esta área foi considerada a mais bela em termos de beleza cênica, sendo possível observar o canyon formado pelo rio Moa (E) ao entrar na Serra da Jaquirana, com seus paredões rochosos, e a caminhada até o topo do Morro Queimado (duração de 3 horas), que oferece uma vista panorâmica do Parque (Associação SOS Amazônia et al., 1998). 
A Geodiversidade, nesse sentido, é demonstrada pelas inúmeras riquezas geológicas, geomorfológicas e fitogeográficas do PNSD. Aliado a essa rica Geodiversidade registram-se conflitos territoriais no local.

\section{b. Conflitos territoriais no PNSD}

A distribuição do povoado nas adjacências e até no interior do PNSD é diversificado (Figura 2). Os povoados locais são distribuídos ao longo do curso dos rios que possuem importância vital para as pessoas. Os cursos de água dessa microrregião são drenados pelo rio Juruá importante afluente da bacia do Amazonas.

Figura 2: Mapa da Ocupação e Uso Fundiário no Acre e entorno do PNSD.

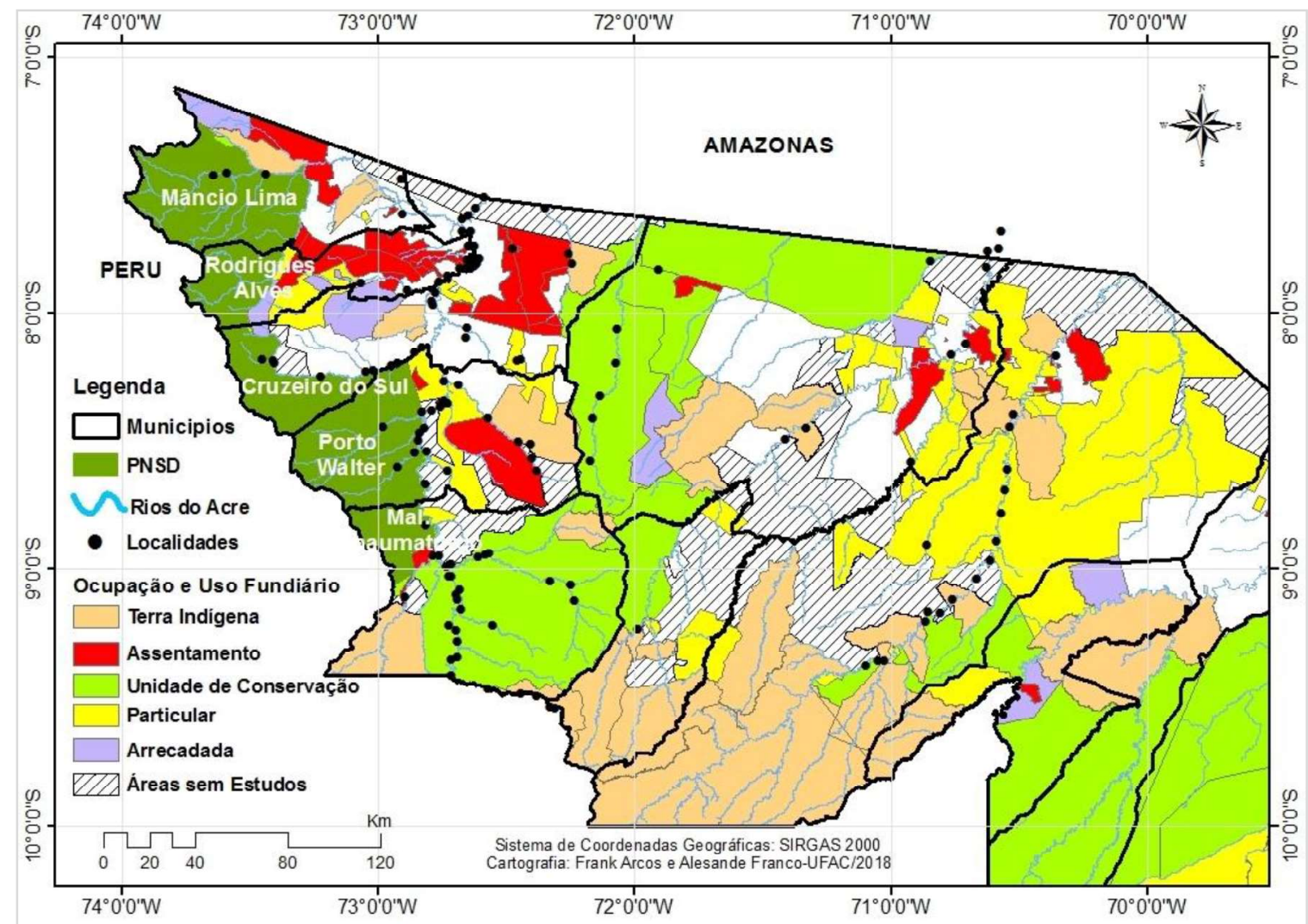

Fonte: ACRE/ZEE (Base digital - 2000 e 2010). Org. pelos autores (2018).

No cartograma a seguir, é possível também observar o mosaico do uso e ocupação presente no local como, terras indígenas, assentamentos e outros elementos constituintes da relação fundiária no interior e entorno do PNSD.

Independente da forma de uso e ocupação do solo, o PNSD também sofre intensiva pressão do entorno devido à ascensão de áreas de fazendas de criação de gado e dos 
assentamentos que dizem respeito ao desmatamento, a supressão de Áreas de Preservação Permanentes (APP's), assoreamento de rios e igarapés, bem como, a redução da fauna e flora. Em grande parte das vezes outros problemas recorrentes são observados à sobreposição de áreas no interior do parque o que traz em pauta questões referentes à gestão da unidade no contexto da intensificação dos conflitos fundiários pela posse da terra no oeste acreano.

Outros fatores que trazem conflitos são: o tráfico de drogas no local em função da área de fronteira e a ação de invasores. Ambos acessam a área do PNSD via estradas clandestinas, rios e igarapés. A ação dos traficantes ocorre com frequência em função da dificuldade em fiscalizar a área devido a sua extensão.

A ação de madeireiros peruanos e brasileiros visa o corte e retirada de madeira de Lei com altíssimo valor comercial. Essa ação deixa um lastro de destruição e insegurança para as comunidades locais devido à falta de fiscalização pelo poder público.

Em Parques Nacionais como o PNSD não se permite a atividade antrópica no seu interior, porém, conforme expresso anteriormente e constatado no inventário do plano de manejo já existiam povoados no Parque, muito embora, esses atores sociais não foram retirados da área e, atualmente convivem em harmonia com a diversidade local de forma que, seu cotidiano não oferece maiores riscos à sustentabilidade sócio ambiental da área.

É possível observar que para o PNSD os efeitos diretos estão ligados à conservação e manutenção dos elementos naturais e das ações voltadas para a proteção do modo de vida de comunidades inseridas em áreas protegidas e, de uso sustentável. Essa relação com a sustentabilidade cria práticas que visam beneficiar atores locais buscando associar a atividade econômica, distribuição de renda e valorização do meio físico com sustentabilidade.

\section{c. As potencialidades Geoturísticas do PNSD}

O geoturismo pode promover a geoconservação, bem como, esta última pode promover o geoturismo, pois ao proporcionar aos turistas uma visão mais científica do que contemplativa da paisagem, o geoturismo acaba por possibilitar a promoção da geoconservação e esta, por sua vez, é ferramenta indispensável na conservação da Geodiversidade mundial, seja ela representada por geossítios ou pelo patrimônio geológico (BENTO; RODRIGUES, 2010a).

No contexto do geoturismo todas as ações devem se coligar as bases do desenvolvimento sustentável. A sustentabilidade ambiental deve ser priorizada, pois, nessa perspectiva ocorrerá diretamente a valoração dos atributos físicos e, de produtos e serviços que 
podem ser criados pelas comunidades locais e, isso vem a propiciar trabalho e geração de renda, de forma que garanta a sustentabilidade ambiental, cultural e socioeconômica.

Um dos pontos de primordial importância é a coparticipação dos atores sociais locais, que vêm, com a possibilidade de ferramentas e o "uso de instrumentos econômicos na gestão ambiental e na política ambiental, como os mecanismos de Compensações por Serviços Ambientais - CSA" (RANDO; BROSE; ARCOS, 2013, p.1), sendo atuantes na promoção da diminuição de desmatamento, proteção da biodiversidade, elementos da geologia e da geomorfologia como patrimônio natural no âmbito do geoturismo no PNSD em toda sua amplitude.

Moreira (2014) argumenta que alguns impactos positivos do geoturismo relacionados à conservação do patrimônio geológico, à geração de empregos diretos e indiretos e à compreensão do ambiente através de uma educação geológica e ambiental dos visitantes, gerando um aumento da consciência da população local e dos turistas quanto ao patrimônio geológico. Já como impactos negativos podem ser citados os danos aos sítios geológicos, decorrentes da utilização excessiva e/ou incorreta, a coleta de souvenirs, vandalismo e remoção ilegal de itens como fósseis e minerais. Além disso, a geração de benefícios econômicos pode ser limitada se a maioria das pessoas empregadas não for da comunidade local.

Como ponto positivo, o PNSD tem todas as características para o Geoturismo, pois, apresenta elementos naturais de ordem geológica que apenas podem ser observados devido à proximidade com os Andes e, da ação resultante de uma tectônica muito influente na região acreana, no entanto, Bento e Rodrigues (2013b) afirmam que o geoturismo e geoconservação podem também ser tomados como indutores do desenvolvimento econômico local, propiciando a gestão e utilização da Geodiversidade, desde que realizada de forma planejada e sustentável.

O PNSD é uma área estratégica para o geoturismo na região amazônica, uma vez, que contemplada ações fomentadoras que visem a capacitação dos atores locais que vivem no interior do parque. Tal ação proporcionará melhorias na qualidade de vida e, incremento nas condições de manutenção e conservação dos elementos bióticos e abióticos que podem por sua vez atribuir valor ao patrimônio natural existente na área.

Com a relevância do parque para o geoturismo como caráter educativo e científico também deve ser levado em consideração à educação que, voltada à conservação do meio natural de certa forma minimizará muitos impactos no parque, por exemplo, a proteção das trilhas de acesso, da subtração de material e contrabando de madeira e o desmatamento. 
Atualmente, um projeto para extinção do PNSD e transformá-lo em uma APA, está em andamento, com intuito de abrir uma BR para ligar a cidade de Cruzeiro de Sul (Acre, Brasil) a Pucallpa (Peru). A viabilidade da integração entre os dois países, sobretudo, entre as duas regiões, através de um projeto de Lei esbarra-se na legislação presente representada pelo Sistema Nacional de Unidades de Conservação (SNUC). Silva-Macher e Farrell (2017) destacam que a construção de modais de transporte no contexto atual da economia política, que prioriza a renda em dinheiro sobre a conservação, provavelmente terá consequências negativas substanciais para a conservação da floresta no Peru e no Brasil e para os meios de subsistência locais em toda a região.

Nesse sentido, com esse artigo queremos de fato levar ao conhecimento da comunidade científica os diversos problemas de ordem ambiental e social que podem surgir com a projeção empírica da referida estrada de ligação na Pan-amazônia. Os valores dentro do contexto da geoconservção ambiental fomentam de forma proativa a manutenção dos geosítios, esculturados durante o tempo geológico na região do oeste acreano. Tais geosítios devem ser preservados e mantidos para que as populações tradicionais que ocupam o interior do PNSD possam usufruir e, se beneficiar com os novos projetos da atividade voltada para o geoturismo regional local.

\section{CONSIDERAÇÕES FINAIS}

O Brasil é rico em paisagens naturais e tem uma Geodiversidade geológica e geomorfológica muito diversificada em todas as suas regiões. Na região Amazônica é possível citar os elementos encontrados no oeste do Acre no interior do Parque Nacional da Serra do Divisor com belas cachoeiras, pequenas grutas, enormes vales fluviais e uma rede hidrográfica que permite o acesso a localidades no PNSD.

No caso do Estado Acre, algumas áreas detentoras de um patrimônio natural específico e, que as estruturas se divergem quando consideramos a sua fase evolutiva no tempo geológico sob o ponto de vista de seu embasamento e diferenças litológicas que algumas ocorrem em apenas um determinado local no estado. Algumas dessas áreas, em especial, PNSD possuem questões de conflitos entre comunidades e gestores.

Os conflitos mencionados são referentes às invasões, tráfico de drogas, retirada ilegal de madeira, potencial exploração de combustíveis fósseis, abertura de estradas e ainda as formas de uso e ocupação da terra no entorno do parque. 
Como forma de amenizar conflitos, o turismo pode ser uma forma de equacionar tais problemas, desde que valorize não apenas o segmento flora e fauna, mas também os elementos da geologia e geomorfologia existentes, dando apoio a geoconservação e valorização do patrimônio natural.

Para que a atividade dentro do PNSD, como o geoturismo ocorra de forma eficiente e sem impactos ambientais, é necessário planejamento e organização. Parece-nos que os termos Geodiversidade, geoturismo e geoconservação, precisam ser difundidos dentro dos planos governamentais municipais, estaduais e federais em áreas que possuem atrativos para tais elementos.

No caso específico do PNSD, os atrativos mencionados são encontrados no local, precisando apenas incremento na organização e efetivação do local, de acordo com Moreira (2014) para o planejamento é importante que sejam realizadas as seguintes fases: inventário dos pontos de interesse, definições de objetivos e metas, desenvolvimento de ações, gerenciamento, avaliação e monitoramento.

\section{REFERÊNCIAS}

ACRE. Governo do Estado do Acre. Programa Estadual de Zoneamento Ecológico Econômico do Estado do Acre. Zoneamento ecológico-econômico: aspectos socioeconômicos e ocupação territorial - documento final. Fase I. Rio Branco: SECTMA, 2000.

ACRE. Secretaria de Estado de Meio Ambiente. Livro temático II: recursos naturais I - geologia, geomorfologia e solos do Acre. Programa Estadual de Zoneamento ecológico-econômico do Acre - Fase II - Escala 1:250.000. - Rio Branco: SEMA: Acre, $2010.104 \mathrm{p}$.

ADAMY, A. Geodiversidade do estado do Acre. Porto Velho: CPRM, 2015a, 321p.

ADAMY, A. Geoglifos de Rondônia: vestígios do passado (2016b). Anais. Disponível em: <http://rigeo.cprm.gov.br/xmlui/handle/doc/17371>. Acesso em: 06/12/2017.

ANDRADE, M. M. N. de; ANDRADE, M. N. de; CARNEIRO, D. de S. (2017): Geodiversidade e geoturismo urbano: estudo de caso em Santarém (PA). Revista Turydes: Turismo y Desarrollo, n. 22 (jun2017). Disponível em: http://www.eumed.net/rev/turydes/22/geoturismo-santarem.html. Acesso em: 06 dez. 2017.

Associação SOS Amazônia; Instituto Brasileiro do Meio Ambiente e dos Recursos Naturais Renováveis; The Nature Conservancy. Plano de manejo do Parque Nacional da Serra do Divisor, Acre - Brasil. Rio Branco, Acre: SOS Amazônia, 1998. 
BENTO, L. C. M; RODRIGUES, S. C. O geoturismo como instrumento em prol da divulgação, valorização e conservação do patrimônio natural abiótico - uma reflexão teórica. Campinas, SeTur/SBE. Turismo e Paisagens Cársticas, 3 (2), 2010a. Disponível em: http://www.sbe.com.br/ptpc/tpc v3 n2 055-65.pdf. Acesso em: 21.nov.2017.

BENTO, L. C. M; RODRIGUES, S. C. Geoturismo em Unidades de Conservação: uma nova tendência ou uma necessidade real? Revista do Departamento de Geografia-USP: São Paulo-SP, v.25, p.77-97, 2013b. Disponível em: https://www.revistas.usp.br/rdg/article/view/75175/78723. Acesso em: 22.nov.2017.

BRASIL. Departamento Nacional da Produção Mineral. Projeto RADAMBRASIL. Folhas SB/SC. 18 Javari/Contamana; geologia, geomorfologia, pedologia, vegetação e uso potencial da terra. Rio de Janeiro, 1977.

BRASIL. Lei n. 9.985, de 16 de julho de 2000. Regulamenta o artigo 225, Parágrafo 1 incisos I, II, III e VII da Constituição Federal, institui o Sistema Nacional de Unidades de Conservação da Natureza e dá outras providências. Brasília: 2000.

BRILHA, J; PEREIRA, D; PEREIRA, P. Geodiversidade: valores e usos. Braga: Universidade do Minho, 2008.

CAMPBELL, K. E.; HEIZLER, M.; FRAILEY, C. D.; ROMERO-PITTMAN, L; PROTERO, D. R. Upper Cenozoic chronostratigraphy of the southwestern Amazon Basin. Geology. v. 29 (7) p. 595-598, 2001.

CAVALCANTE, L. M. Aspectos geológicos do estado do Acre e implicações na evolução da paisagem. Rio Branco, AC: Embrapa Acre, 2006.

CPRM. Mapa Geodiversidade do Brasil. Escala 1:2.500.000. In: Geodiversidade do Brasil: conhecer o passado, para entender o presente e prever o futuro. Rio de Janeiro: CPRM, 2006. 264 p.: il.: $28 \mathrm{~cm}$. (Cap. III, Origem das paisagens, p. 33).

DOWLING R. Geotourism's contribution to Local and Regional Development. In: NETO DE CARVALHO, C; RODRIGUES J. C. Eds. 2009. Geoturismo \& Desenvolvimento Local. Idanha-a-Nova/PT. p.15-37.

GALOPIM DE CARVALHO, A.M. Natureza: biodiversidade e Geodiversidade. 11 maio 2007. Disponível em: http://terraquegira.blogspot.com/2007/05/natureza-biodiversidadee.html. Acesso em: 06 mar. 2018.

ICMBio. Instituto Chico Mendes de Conservação da Biodiversidade. Limites das Unidades de Conservação Federais. Disponível em: http://www.icmbio.gov.br. Acesso em: 13 dez. 2017.

LANI, J. L; AMARAL, E. F; ARAÚJO, E. A; BARDALES, N. G; SCHAEFER, C. E. G.R; MENDONÇA, B. A. F. Geologia e relevo: alicerces da paisagem Acreana. In: ARAUJO, E. A; LANI, J. L. (Org.). Uso sustentável dos ecossistemas de pastagens cultivadas na Amazônia Ocidental. Rio Branco: SEMA, 2012, v.1, p.09-37. 
LIRA, E. M. de. A criação do Parque Nacional da Serra do Divisor no Acre (1989) e sua inserção nas políticas federais de implantação de Unidades de Conservação federais no Brasil. 2015. Tese (Doutorado) Programa de Pós-Graduação em História Social, do Departamento de História da Faculdade de Filosofia, Letras e Ciências Humanas. Universidade de São Paulo-USP. São Paulo, 2015, 247p.

SILVA-MARCHER; FARRELL. Explorando futuros para a Serra do Divisor da Amazônia: uma abordagem triádica de avaliação ambiental para analisar escolhas de decisões econômicas ecológicas no contexto de grandes mudanças nas condições de contorno. Ecologia Econômica, V. 141, Nov, 2017 , páginas 166-179.

MOREIRA, J. C. TURISMO EM ÁREAS NATURAIS E O GEOTURISMO. In: Geoturismo e interpretação ambiental. 1. ed. rev. atual. Ponta Grossa: Editora UEPG, 2014. 157p.

RANCY, A. Paleoecologia da Amazônia: Megafauna do Pleistoceno. Florianópolis: Editora da UFSC. 2000. 102p.

RANDO, A. S; BROSE, M. I; ARCOS, F. O. Salvaguardas sociais e ambientais do sistema estadual de incentivos a serviços ambientais: relato da experiência no Acre. IV Seminário Internacional sobre Desenvolvimento Regional. Santa Cruz do Sul, RS, Brasil, 2013. Disponível em: http://www.unisc.br/site/sidr/2013/Textos/216.pdf. Acesso em: 14 dez. 2017.

SANTOS, J. C. R. dos; RANCY, A; FERIGOLO, J. Octodontobradyinae: Nova Subfamília de Orophodontidae (Edentata, Tardigrada). Descrição de Porção do Crânio e Mandíbula de Octodontobradys puruensis, Gen. N., SP. N., Procedente do Neógeno o Estado do Amazonas, Brasil. In: Congresso Brasileiro de Paleontologia, 12, São Paulo. Anais. p. 35. 1991.

VEIGA, T. A Geodiversidade do cerrado. Brasília, DF: Pequi - Pesquisa e Conservação do Cerrado, 2002. Disponível em: http://www.pequi.org.br/geologia.html. Acesso: 6 maio 2018.

VERAS, A. S. S. A Paisagem como recurso e o geoturismo como possibilidade em Mucajaí - RR. 90f. Dissertação (Mestrado em Geografia). Programa de Pós-Graduação em Geografia. Universidade Federal de Roraima (UFRR). Boa Vista-RR, 2014. 